\title{
THE EMERGENT CITY. INTERACTIVE RELATIONAL SYSTEMS BETWEEN PUBLIC ADMINISTRATION AND CITIZEN TO FOSTER SUSTAINABLE PROCESSES OF URBAN DEVELOPMENT
}

\author{
Author(s) / Auteur(s) : \\ Valentina VOLPI $I^{1,2}$ \\ ${ }^{1} P h D$ Student in Interaction Design \\ ISIA Roma Design \\ ${ }^{2}$ Research Assistant \\ Link Campus University, Rome \\ valentina.volpi84@gmail.com \\ Mauro PALATUCCI \\ Professor in Interaction Design \\ ISIA Roma Design \\ mauro.palatucci@gmail.com \\ Giuseppe MARINELLI DE MARCO \\ Architect, Professor in Basic Design and Meta-design \\ ISIA Roma Design \\ marinelligiu@tiscali.it
}

\begin{abstract}
Résumé :
The widespread of Information and Communication Technologies and the consequently redefinition of roles in the usage and management of the city brought along new systems of relationships and interactions that produce an auto-organisation of territories or communities, showed also through temporary transformation of the environment. In effect, cities are continuously redefined by emergent properties that may, both be originated and then impact on social, political, cultural, and economical people practices. On the other hand, through the arrangement of its patterns the city shapes the social and connective relations occurring among people. So, the city can be regarded as a complex system, that in the last years has been expanded by the widespread of communication devices and sensors connected to the Internet. In this context, the design of new patterns of interactions that focuses on the new relationship opportunities, in part offered by the Information and Communication Technologies, but not limited to them, may significantly affect sustainable processes of urban development. This paper focuses on the civic aspect of the so-called smart cities, and, in details, on the relation between citizens and Public Administration. Some existing interaction patterns are illustrated in order to support the visualisation of the dynamic relationships between citizens and Public Administration, while new possible relations derived by the interaction with the urban space are supposed.
\end{abstract}

Keywords / Mots-clés :

interaction patterns, Public Administration, citizen, relational system, smart city, information and communication technologies, meta-design, complexity

\section{INTRODUCTION}

The urban space has been highly influenced and transformed by the evolution of Information and Communication Technologies (hereafter ICTs). On the one hand, technologies have been integrated into much traditional street furniture, such as streetlamps, traffic lights, bus stops, even memorials, or have became themselves street furniture, such as public screens and totems, changing the overall look of the city. On the other hand, technologies have induced new habits and behaviours, changing the relations and the interaction modes occurring into the city. For example, the development of transport sharing services generally based on online platforms accessible via desktop or mobile devices, affected the interaction modes between the city users and the urban transportation system. At the same time these practices of shared mobility (such as other practices based on sharing and participation 
belonging to other sectors) have been made possible by the widespread use of ICTs, and Internet over all, that fostered information reuse and user engagement.

In effect, the widespread adoption of ICTs and digital media changed the cognitive models and generated several processes of emergence that re-define the relational systems occurred in the city. For example, de Kerckhove (de Kerckhove, 2010) uses the term "augmented mind" to refer to the common concept of mind "inside our heads, but externalized, shared, multiplied, accelerated, randomly accessed and generally processed in a connective way outside our heads". The augmented mind is the consequence of the invention and use of the new electronic media, which support and export language augmenting the mind outside our heads. This augmentation and acceleration of the user's mind is also "the spontaneous formation and aggregation of minds, performing different collaborative functions to achieve a myriad of individual or group aims and initiatives". It is a "connective mind" (de Kerckhove, 2010).

This does not have to lead to a techno-centric vision of the city. On the contrary, it led to reflect on how the relations between people and city are changing into a highly interconnected system, in order to identifying new interaction patterns fostering sustainable processes of urban development. According to Conlon (Conlon, 2008), the Interaction Design should examine "how the user appropriates technology as needed to shape personalized relationship and relationship opportunities with other users". In the last years the appropriation of technologies by the users for the achievement of civic and common interests gained more and more importance into the decision-making and planning processes of the city. For this reason, it should be interest of the Public Administration looks at Interaction Design as the key to the development of a formative and fertile relationship with the citizens. The focus on relation rather than on functionalities opens to a wider field of research able to foster the development processes of the city and the intrinsic qualities of urban life.

Nowadays technologies aimed to collect and manage large and various amount of data and information in order to capture emotions and needs of city users seem to greatly affect the currently urbanization processes and the activities of the city users. This information flow, managed through complex calculation systems, is regarded as a "smart" attitude in the city, which appears able to sustain the development processes. But, in effect it represents a source of fragmentation and information overload for the common citizen. On the contrary, thinking to the city in a qualitative way, as a system of relational opportunities, gives larger importance to the consistencies of the system.

In this paper we focus on the relational systems between citizen and Public Administration. So, first of all, we define and discuss the context and the main topics of the research, i.e. the city, regarded as a system continuously transforming itself and observed through the smart city paradigm, and the redefinition of relations and roles between citizen and Public Administration. Then, we illustrate as patterns of interaction some dynamic relations currently occurring between citizens and Public Administration. Finally, we supposed which would be a possible approach looking at new relational opportunities between citizen and Public Administration derived by the interaction with physical and virtual elements of the urban space.

\section{THE EMERGENT PATTERNS OF THE "SMART" CITY}

The city is the physical and equally ideal place where the relational systems between citizens and Public Administration occurred. It can be regarded as a complex system, where different urban structures, susceptible to change in respect of the effective use made of them, emerge from the different combination of architectural and social elements. In effect, the evolution of the city over time sees the creation, the demolition, and the re-creation of different emergent patterns through the actualization of repeated actions, in order to find a balance among the different forces that compose the system. Along with Minati (Minati, 2008), all these forces forge the identity of the city as an emergent property continuously acquired, rather than possessed. In detail, the city is constantly redefined by emergent properties that produce an auto-organisation of a territory or a community showed also through temporary transformation of the environment. People are one of the main sources of changeable emergent properties that affected the city. At the same time, the arrangement of the city 
patterns (Alexander, 1977) shapes the social and connective relations among the city users, included the Public Administration. So, the city can be regarded as a complex system of information. The widespread of communication devices and sensors connected to the Internet expands this system. This let citizens have a deeper acknowledgment of the city, but may cause, at the same time, negative effects leading to great inequality (Moser, 2001), such as information fragmentation and overload, that people has to manage every time he/she uses a service or "lives" a city. For example, an uncontrolled and unmanageable use of technologies may foster the only advance of strong communities or organized groups and act as a sounding board for complaints and demagogic attitudes.

Anyway, technologies are a significant force that continues to change the organization of cities and communities. In effect, the concept of "smart communities" originated from the wider range of opportunities for government and commerce offered by the realization of citizens' networks collaborating through ICTs in order to foster local economy (Moser, 2001). The relations among people, sustained by technologies, created value and competitive advantage for the territories, that inevitably changed them.

In the course of time, the city has been characterised by stressing many of its attributes or a combination of them. "Smart" is one of its labels (Hollands, 2008), largely used to vehicle some "city patterns" derived or expected from the current urban development phenomena. In detail, "Smart city" is a term that refers to a concept assuming many aspects and meanings on the basis of the different context or of the different scientific and professional point of view of the observer. A different connotation may be given to this concept by replacing the word "smart" with other adjectives. Anyway, it may refer to the general attitude of the city to capture opportunities and to adapt itself to emerging needs and contingencies by effectively and efficiently using the available resources. In such a way, the different kind of smartness to apply varies with the city and with the field of application. In general, as it results from the study of Caragliu (Caragliu 2011), the smartness does not depend only on the ICTs infrastructure, but also on "the availability and quality of knowledge communication and social infrastructure". Anyway, according to Chourabi (Chourabi, 2012), "technology may be considered as a meta-factor in smart city initiatives", since in some way it influences the other factors.

In concluding, smart city should assure an organic connection between its different components, including technologies (Nam, 2011), which, in effect, can stimulate civic engagement in the processes of public interest. Smart city is not a static entity. It continuously changes and adapts itself in accordance to the elements and processes that emerge within the smart city system.

\section{THE “OPEN" INTERACTION BETWEEN CITIZEN AND PA}

As a consequence of the widespread of Internet and digital media, in the last years citizens have acquired different roles and responsibilities taking them to the centre of the decision-making processes of the Public Administration, as sources of innovation bringing value into the system. Beyond being voters and taxpayers, citizens have gained new roles that potentially let emerge new types of relation with the Public Administration, for example as city users and sources of innovation for the whole system (Koch, 2013; Schuurman, 2012).

The network of relations originated in such a way affected the economic, cultural, political, and social practices of territories, increasing the value of concepts such as sharing economy and social innovation, that in effect can be seen as a condition verifiable only if a specific process of development impacts in a sustainable way on economic, social, and environmental sectors at the same time.

By adopting an Open Government approach (founded on transparency, participation, and collaboration), the Public Administration has facilitated these processes. But at the same time the new attitudes and emerging needs of citizens, originated from the transformation of practices led by Internet and the digital media, gave no choice (thanks to their strength) to the Public Administration, that had to move from be a closed system, to be an open one. 
The system of relations occurring between citizens and Public Administration is only one of the systems composing the city and that are connected in an organic way to the processes until now described in this paper.

The complex interdependence among the numerous interactions taking place in a city and the widespread of the sense of a civic-mindedness based on sharing leads Public Administration to the need of building a solid relationship with citizens. In detail, because of its public and administrative role, the actions of the Public Administration should be oriented to find solutions improving the relationship between city and society and, consequently, between citizens and Public Administration itself. Moreover, a more collaborative and open Public Administration can respond more appropriately to the needs of a territory or community with effective and efficient services, facilitating the processes of land development. It is responsibility of the Public Administration to lead citizens through a really formative participation and, in turn, becomes really responsive to demands and emerging needs from the society, since not all citizens are engaged in the same way, but they all are subject as city users to the sphere of interest of the Public Administration. According to De Toffol, (De Toffol, 2012) "cities are schools and laboratories to pass from government to governance; but this implies an increasing in capabilities (individual, collective, institutional) and a radical change in languages, procedures, and government tools". Although, Public Administration tends to focus first of all on legal and regulative aspects regarding the new role of the citizen (because of its institutional role), the radical change needed in languages, procedures, and government tools has to concern others types of disciplines as well, since they are all aspect of the same complex system of interactions. So, the architectural patterns of the city may support or encourage interaction patterns and contribute to form the relation between citizen and Public Administration. And, also design can contribute to the process of social change in a sustainable way, by identifying new interaction paradigms from a systemic perspective.

Moreover, besides marking the direct relations between citizens and Public Administration, that often bring conflicts that block the processes of change, it is needed to look at indirect relations, less visible and recognizable, that may let the process proceed by producing the favourable situation for change to happen. In this sense, Interaction Design allows to explore possibilities about the patterns of interaction, in order to stimulate and explore future city's configurations.

In this regard, the use of ICTs allows very flexible and scattered interactions between citizens and Public Administration introducing open processes of inclusion and exclusion in the system. That is to say that citizens are not forced on a fixed type of interaction, but they can both accept or not the intervention of the Public Administration at different times. In such a way, a dynamic process of participation originates from the relation between citizen and Public Administration. It takes different forms, but it remains consistent with the whole system. For example, the intervention of the Public Administration on a certain territory could bring to a gradual (by stages and extended over time) involvement of the citizen within a process more and more aimed at achieving a common goal, as for co-design processes. Here the process of participation is likely to assume the shape of a spiral direct towards the centre, but in a different moment or towards a different goal the adoption of a more pervasive interaction pattern could be more appropriate. So, information or services without a specific address could be widespread as drops of rain all around, such as in the case of the platform for the creation and use of open data. In Figure 1 some other examples are reported.

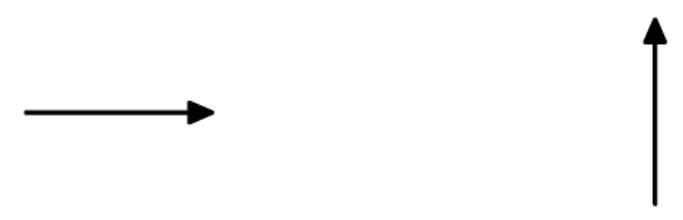

DIRECT RELATION

(on the same level)

Unidirectional relation between peers, linear (e.g. citizen sourcing for
DIRECT RELATION

\section{(top-down)}

Top-down unidirectional relation, linear (e.g. collecting citizen's data for open

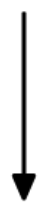

\section{DIRECT RELATION}

(bottom-up)

Bottom-up unidirectional relation, linear (e.g. e-government services). 
communities services)

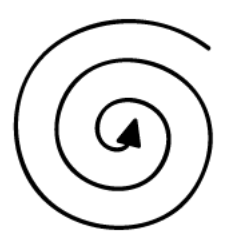

SPIRAL RELATION

(towards the centre)

Gradual engagement, step by step, within a long period process, more and more oriented to the achievement of a common aim (e.g. co-design)

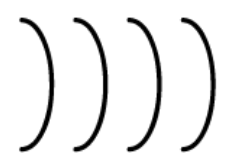

\section{WAVES RELATION}

Propagation of services or information on the basis of a repeated scheme aiming to collect, intercept, or hit similar resources (e.g. word-ofmouth-based services or shared services, as car sharing e bike sharing)

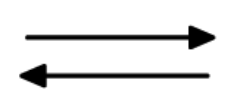

\section{BIDIRECTIONAL RELATION}

\section{(among peers)}

Direct and linear exchange of information and services based on a lowly engaging peer-to-peer relation (e.g. swapping platforms)

government services)

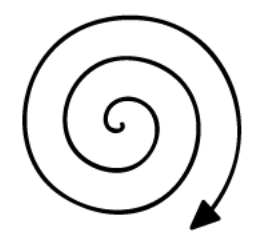

SPIRAL RELATION

(from the centre)

Gradual enlargement of the relation, that, with the passage of time, engage an increasing amount of resources (e.g. local development processes)

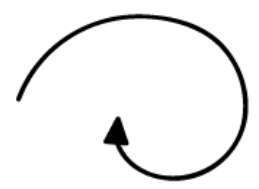

\section{ENVELOPING RELATION}

Objective achievement through apparently informal routes, lowly predictable, but immediately engaging (e.g. gamification or participatory maps)

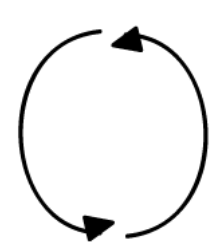

\section{CIRCULAR RELATION}

(top-down or bottom-up)

Circular exchange of information and services based on a middle engaging hierarchical relation (e.g. call for ideas)

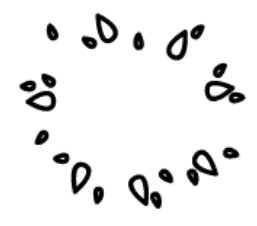

\section{RAIN DROPS RELATION}

Scattered widespread of information and services (e.g. open data platform)

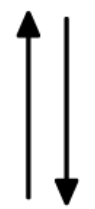

\section{BIDIRECTIONAL RELATION}

(top-down or bottom-up)

Direct and linear exchange of information and services based on a lowly engaging hierarchical relation (e.g. public consultation or transaction)

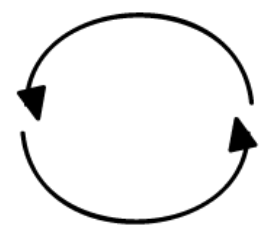

\section{CIRCULAR RELATION}

(among peers)

Circular exchange of information and services based on a middle engaging peer-to-peer relation (e.g. car pooling)

Figure 1. Some patterns of interactions between citizen and Public Administration

These and more interaction patterns that could be applied to the process of participation are the result of the correlation of different variables of the observed system, such as technology, motivation, level of engagement, etc. They try to represent the "urban complexity" (Guida, 2013) by showing a possible relational and communicational system likely traceable on the territory, so that they can be put in relation to the urban space as meta-design tools supporting the visualisation of the dynamic relationships between citizens and Public Administration. The Public Administration may use them as schemes interpreting the processes occurring in the physical and virtual space of the city, in order to elaborate strategies and better relational approaches. 


\section{BUILDING THE RELATION BETWEEN CITIZEN AND PA}

Assumed the city as a system continuously transforming itself, because of emergent elements, we considered the interactions occurring in it as part of continuous processes involving its different parts.

Nonetheless, we observed that the analytical approach, largely used to define if a city is "smart" or not and to satisfy its needs, aims to reduce the complexity of the interactions and relations that occurred into the city, focusing on its parts rather than on the whole. The result is standardization and clinical monitoring of the city processes. Moreover, the analysis of criticalities and needs of the smart city and its users, based on classifying and measuring the initiatives of the city or tracing and collecting information and data from people, objects, and almost "everything", contribute to produce information fragmentation and overload.

Clearly, the analytical approach has not to be excluded from the theoretical tools used for studying and managing the city, but, next to it, we need to put an "oriented-to-process" approach, in order to more appropriately manage the continuous transformation of the system.

So we borrowed some key concept from the oriental philosophy and practice (Chieng, 2007), founded on the process concept, and we applied them to the relation between citizen and Public Administration in order to explore the possible interaction patterns. In detail, the main key concept we take into account are: 1) relation as basis for definition of things; 2) ineffectiveness of fixed models; 3) reasoning geared towards the deployment of a possible route consisting of several connected phases, where the identification of a main path does not exclude other paths that intersect and temporarily border on it; 4) dynamic relations (continuous change); 5) holistic approach; 6) process not aimed to a perfect solution (from one well-defined point straight to an other well-defined as well), but to a continuous transformation open to various possibilities; 7) indirect and subtle effect (gradual and not forced change, evolving with the whole process and influenced by strategies).

So, in order to build a solid and effective relation between citizen and Public Administration (essential condition for foster sustainable processes of urban development), the latter should operate in the direction of gradually transforming a specific situation by encourage the favourable elements derived from the situation itself, without pointing directly to an effect by imposing its own plan of action. The Public Administration should prepare the background for the final result, when a transformation becomes clear and established.

Along with the role of administrator, Public Administration should assume the role of facilitator of the city's (unavoidable) changes, which derive from citizens needs and, in general, from the emerging processes affecting the city. In this way the Public Administration could influence specific situations towards a sustainable urban development by offering citizens new relationship opportunities with other citizens. Again, Interaction Design can help to do this in a non-invasive and non-disfiguring way.

Nowadays, digital places are the faster and most visible way to put in connection citizen and Public Administration. Online institutional sites, participation or services platforms, social networks, etc. put into direct contact citizen and Public Administration. They trace a direct line between them. Although they contribute to open the interaction between citizen and Public Administration, these tools of communication and interaction are mostly suited for active users and are mostly oriented to action and efficient problem solving. On the other hand, they require the consumption of large quantity of resources, such as time and information. Moreover, these tools, that can be called "civic technologies" (i.e. technologies aimed to promote civic and social engagement in the processes of common interest, making national or local policies more effective), risk to add fragmentation and disorientation into the citizen life, besides to standardize some participation processes (e.g. adding markers on a map to report some problems). Thinking about the kind of relation established, the risk is that the citizen awaits for an effective and quick response from the Public Administration, a real and immediately clear act of change, as direct consequence of its active participation. If this can be considered as needed and licit in the dialog between citizen and Public Administration, it represents only one (or more) part of the whole process of urban development. 
So, besides the use of online platform, properly designed for enhancing worthwhile participation, the relation between citizen and Public Administration has to be enriched of interaction patterns not adapted to rigid models, but emerged from the interaction process itself.

In this sense, the Public Administration should not force people to participate, only rewarding the active behaviour, or impose where, when and how do it (at least not always). Public Administration should instead be perceived as a fair presence both in the virtual and the physical world. If the city is the physical space of interaction between citizen and Public Administration, nowadays this physical place has to be considered as permeated of digital places; and all these places enter as experiences into the citizen life.

In this sense Bratton (Bratton, 2008) talk about the "convergence of architecture and interface design as the chain of successive interactions extends all the way down into global and local networks of systemic interconnectivity, including and dependent upon concrete, tangibly embedded interfaces like buildings, cables, and cities". Moreover we notice that, in considering architecture and interaction design as interested in the same problem of "program" human-related interfaces, although with different tools, Bratton adopted a holistic concern. "Information technologies and social systems of spatial formation, interaction, signification, emergence, and complexity always commingle and codetermine each other" (Bratton, 2008).

So, the relation between citizen and Public Administration should not only be perceived as virtual. It should have effect on the territory. Of course it may start in the digital world, by the action of an online community, and then coming into the real world with a high impact transformation, such as the realization of a shared garden or place to co-work.

For this reason, it is important to put in relation citizen and Public Administration, and the two with the physical places that they shared. In detail, the research of interaction patterns between citizen and Public Administration may focus on the identification of one or more systems of attraction in the city that mark their interactive relational systems. The "attractor", recognised as a system connected to Public Administration, should aim to multiply the relational opportunities among citizens. For example, it can be a public bench offering the opportunity, thanks to technologies, to experience the city from several points of view by connecting with a network of other benches (or better, citizens) diffused within the city. Since the bench is strictly linked to a place and can inspire reflection, as it imposes to stop in a specific place, it can create a relation with that place and, by extending, with the whole city. By acquiring new meanings as a consequence of new patterns of interaction, the object is no more in a closed relation with the system, but it is open to new interactive relational modes influenced by context and people intervention. In this way, the interaction design of a possible system of attraction aspires to be strategic, projective, and innovative, as in general architecture and design are.

\section{CONCLUSIONS AND FUTURE WORK}

The debate about smart city usually puts a strong emphasis on technology and city performance monitoring as a source of intelligence. Anyway, in the last years a more organic vision of the city as a system connecting people, technology, and governance as interacting parts gained attention. In this context, interaction design may help to explore new interactive relational systems that foster sustainable urban development processes. In the paper, great attention is paid to the relation between citizen and Public Administration and some conditions are put in order to find new possible interactive relational systems. In detail, we concentrate on the correlation between physical and digital interactions within the city through systems of attraction putting the citizen in relation with other citizens and Public Administration. Future work will explore in depth the design of systems of attraction recoding known objects and elements of the city by combining functionality and poetic, and giving them new features that affect social practices. 


\section{RÉFÉRENCES}

Alexander, C., Ishikawa, S., \& Silverstein, M. (1977). A Pattern Language: Towns, Buildings, Construction. The Oxford University Press, New York.

Bratton, B. H. (2008). "What do we mean by "Program"?: the convergence of architecture and interface design". interactions, 15(3):20-26.

Caragliu, A., Del Bo, C., \& Nijkamp, P. (2011). "Smart cities in Europe". Journal of Urban Technology, 18(2):65-82.

Chourabi, H., Nam, T., Walker, S., Gil-Garcia, J. R., Mellouli, S., Nahon, K., Pardo, T. A., \& Scholl, H. J. (2012). "Understanding Smart Cities: An Integrative Framework". Proceedings of the 2012 45th Hawaii International Conference on System Sciences. IEEE Computer Society, Washington, DC, 2289-2297.

Conlon, K. (2008). "The future of interaction design as an academic program of study". interactions, 15(2):38-41.

de Kerckhove, D. (2010). The augmented mind. Digitpub, Milano.

De Toffol, F., \& Valastro, A. (2012). Dizionario di democrazia partecipativa. Centro Studi Giuridici e Politici della Regione Umbria, Perugia.

Guida, G. (2013). Punto, linea, città. Schizzi, schemi e mappe nel progetto urbanistico. CLEAN Edizioni, Napoli.

Hollands, R. G. (2008). “Will the real smart city please stand up?”. City, 12(3):303-320.

Koch, G., Hutter, K., Decarli, P., Hilgers, D., \& Fuller, J. (2013). "Identifying Participants' Roles in Open Government Platforms and Its Impact on Community Growth". Proceedings of the 2013 46th Hawaii International Conference on System Sciences. IEEE Computer Society, Washington, DC, 1900-1910.

Minati, G. (2008). Systemics and emergence for Architecture. In memory of Professor G. Ciribini Gianfranco Minati Italian Systems Society www.AIRS.it doctoral lecturer on systems science. Polytechnic University of Milan, Department "Building Environment Sciences and Technology".

Moser, M. A. (2001). "What is smart about the smart communities movement?". EJournal, 10/11(1).

Nam, T., \& Pardo, T. (2011). "Conceptualizing smart city with dimensions of technology, people, and institutions". Proceedings of the 12th Annual International Digital Government Research Conference: Digital Government Innovation in Challenging Times, ACM, New York, 282-291.

Schuurman, D., Baccarne, B., De Marez, L., \& Mechant, P. (2012). "Smart ideas for smart cities: investigating crowdsourcing for generating and selecting ideas for ICT innovation in a city context". Journal of Theoretical and Applied Electronic Commerce Research, 7(3):49-62. 